\title{
Effects of intraspecific competition on size variation and reproductive allocation in a clonal plant
}

\author{
Mark van Kleunen, Markus Fischer and Bernhard Schmid
}

\begin{abstract}
van Kleunen, M., Fischer, M. and Schmid, B. 2001. Effects of intraspecific competition on size variation and reproductive allocation in a clonal plant. - Oikos 94 . $515-524$.
\end{abstract}

Clonal plants grow in diameter rather than height, and therefore competition among genets is likely to be symmetric and to result in smaller variation in size of genets than in non-clonal plants. Moreover, clonal plants can reproduce both sexually and vegetatively. We studied the effects of density on the size of rosettes and of clones, variation in the size of rosettes and of clones, and allocation to sexual and vegetative reproduction in the clonal herb Ranunculus reptans. We grew plants from an artificial population of $R$. reptans in 32 trays at two densities. After four months, differences in density were still apparent, although clones in the low-density treatment had on average $155 \%$ more rosettes and $227 \%$ more rooted rosettes than clones in the high-density treatment. The coefficient of variation of these measures of clone size was $15 \%$ and $83 \%$ higher, respectively, in the low-density treatment. This indicates that intraspecific competition among clones of $R$. reptans is symmetric and increases the effective population size. Rooted rosettes were larger and varied more in size in the low-density treatment. The relative allocation of the populations to sexual and to vegetative reproduction was $19 \%$ and $13 \%$ higher, respectively, in the high-density treatment. Moreover, seeds produced in the high-density treatment had a $24 \%$ higher mass and a $7 \%$ higher germination percentage. This suggests that with increasing density, allocation to sexual reproduction increases more than allocation to vegetative reproduction in $R$. reptans, which corresponds to the response of some other species with a spreading growth form but not of species with a compact growth form. We conclude that intraspecific competition is an important factor in the life-history evolution of $R$. reptans because intraspecific competition affects its clonal life-history traits and may affect evolutionary processes such as genetic drift and selection through its effect on the effective population size.

M. van Kleunen, M. Fischer and B. Schmid, Institut für Umweltwissenschaften, Universität Zürich, Wintherthurerstr. 190, CH-8057 Zürich, Switzerland (vkleunen@ uwinst.unizh.ch).

"God a'mighty, if I was alone I could live so easy." (John Steinbeck 1937, Of mice and men)

In populations of clonal plants, shoof densities may become very high as a consequence of vegetative reproduction. Plant density may through an increase in intraspecific competition play an important role in the life-history evolution of plants (MacArthur and Wilson 1967, Begon 1982). Intraspecific competition may affect the fitness of clonal plants through changes both in growth and in reproductive allocation. Furthermore, competition may affect the distribution of plant sizes and reproductive values in a population and, as a consequence, the effective population size and genetic structure of the population (Gottlieb 1977, Heywood 1986, Hartl and Clark 1994).

Because clonal plants can reproduce both sexually and vegetatively, intraspecific competition may refer to both competition among genets (i.e. colonies of connected ramets) and among individual ramets (Sackville Hamilton et al. 1987, Schmid 1990). What finally 
counts for evolution, however, is competition at the genet level. While there are several studies on competitive interactions among ramets of clonal plants (de Kroon et al. 1992, Hara et al. 1993, Suzuki 1994 Suzuki and Hutchings 1997), studies on the effect of competition on size variation among genets of clonal plants are scarce (de Kroon et al. 1992, Meyer and Schmid 1999).

Size variation among plants generally increases when there is competition for light because large individuals may overshadow and thus suppress the growth of smaller ones (i.e. asymmetric competition; Weiner and Thomas 1986, Weiner 1988). However, because clonal plants increase in diameter when they grow and only to a limited extent in height, competition among genets of clonal plants is likely to be more symmetric than competition in non-clonal plants (de Kroon et al. 1992 Hara 1994). This implies that variation in size and reproduction among genets should not increase or may even decrease with increased intraspecific competition in clonal plants (Weiner and Thomas 1986).

In clonal plants, there may be a trade-off between sexual and vegetative reproduction as a consequence of a limited availability of resources and meristems (Harper 1977, Watson 1984). There is no general consensus on which response in allocation to both modes of reproduction is most favourable when density increases (Loehle 1987). The response to selection under different densities (i.e. $r$ - and $K$-selection) may depend on whether the clonal plant has a compact or a spreading growth form (i.e. phalanx or guerrilla growth form sensu Lovett Doust 1981, Sackville Hamilton et al 1987). A higher relative allocation to sexual reproduction under high density has the advantage that seed dispersal may act as an escape mechanism from the unfavourable site (Ogden 1974, Abrahamson 1975, 1980, Williams 1975, Loehle 1987, Gardner and Mangel 1999). Moreover, because of recombination, sexual reproduction may result in offspring that have a higher performance in the high-density environment than their parents. However, an increase in allocation to vegetative reproduction under high density may increase the competitive strength of plants (Loehle 1987). In addition, differences in relative allocation to sexual and vegetative reproduction may also be a consequence of different minimum size requirements (Hartnett 1990, Schmid et al. 1995). Furthermore, they could also result from allometric growth, i.e. increased allocation to sexual reproduction with increased plant size (Weiner 1988). In contrast, relative allocation to vegetative reproduction seems to be often constant over a larger range of plant sizes (Dong and de Kroon 1994, Schmid et al. 1995). Therefore, if increasing plant density reduces plant size, it may concomitantly reduce the relative allocation to sexual reproduction.

We investigated effects of intraspecific competition on the effective population size and on life-history traits of the stoloniferous herb Ranunculus reptans. This species is likely to experience different levels of intraspecific competition in nature because it grows in varying densities on periodically inundated lake shores with low vegetation cover (Prati 1998). In 16 experimental greenhouse populations of low density and 16 populations of high density, we studied the size of and the variation in size among individual rosettes and among clones, allocation to vegetative and sexual reproduction, and seed quality.

We asked the following questions: (1) Does increased density reduce the size of clones and the size variation among clones of $R$. reptans? (2) Does increased density reduce the size of rosettes and the size variation among rosettes of $R$. reptans? (3) How is the relative allocation to sexual and vegetative reproduction affected by density in $R$. reptans? (4) How is the quality of seeds affected by density in $R$. reptans?

\section{Materials and methods}

\section{Study species}

The stoloniferous, rosette-forming herb Ranunculus reptans L. (Ranunculaceae) has a circumpolar distribution, mainly in the temperate to boreal-subarctic zones of Europe, Asia, and North America (Hess et al. 1980). The species has a strict habitat requirement and in Central Europe only grows on periodically inundated lake shores with low vegetation cover. In Central Europe, most populations are found around Lake Constance. Within these populations, there is a gradient between two microhabitats. Plants growing close to the winter water line at the lake experience an average summer-inundation period of $150 \mathrm{~d}$ and little competition with other species. In contrast, plants growing about $30 \mathrm{~cm}$ higher and $5-10 \mathrm{~m}$ further away from the lake experience an average summer-inundation period of $80 \mathrm{~d}$ and competition with graminoids, most commonly Agrostis stolonifera (Prati 1998).

Rosettes (i.e. ramets) of $R$. reptans may grow up to 20 leaves. Leaf blades are $10-50 \mathrm{~mm}$ long and $1-5 \mathrm{~mm}$ wide and gradually narrow into the petioles. Rosettes form stolon branches from axillary meristems. Stolons grow sympodially and consist of rosettes connected by thin $(0.5-2.0 \mathrm{~mm}$ diameter) stolon internodes with a length of $3-5 \mathrm{~cm}$. Stolon branches can grow $10-20 \mathrm{~cm}$ within one growing season, which may result in high rosette densities. Each stolon node (i.e. rosette) has the potential to produce one single flower, which develops already before the actual leaf rosette is formed, and roots. As a consequence, vegetative and sexual reproduction are not mutually exclusive in $R$. reptans. The slightly protandrous flowers of the self-incompatible $R$. reptans can produce 10-20 seeds (Prati and Peintinger 2000). The production of stolon branches is interrupted 
by the summer-inundation period, during which existing stolon internodes decay (Daniel Prati, Umweltforschungszentrum Leipzig-Halle, Germany, pers. comm.). Plants overwinter as small, short-leaved rosettes (Prati and Peintinger 2000).

\section{Plant material}

To have a representative sample of $R$. reptans from Central Europe, we collected 40 plants from 10 natural populations around Lake Constance in 1995 and 1997. In all populations, plants were collected close to the winter water line and $5 \mathrm{~m}$ further landwards. Distances between the sampled plants were $\geq 5 \mathrm{~m}$ in all cases, and RAPD analysis revealed that all 40 plants represented different genotypes (Fischer et al. 2000). The collected plants were propagated repeatedly, and vegetative offspring were kept in $40 \times 70-\mathrm{cm}$ trays filled with a 4:1 mixture of sand and compost. On 8 August 1997, we founded 32 artificial populations each with plants from all 40 genotypes in thirty-two $31 \times 44-\mathrm{cm}$ trays filled with a $4: 1$ mixture of sand and compost. Both the precultivation of plants and the experiment described below took place in a plant room at $25^{\circ} \mathrm{C}$ with $16 \mathrm{~h}$ of artificial light. The plants were fertilized once with a commercial NPK fertilizer (POKON, Bendien BV, Naarden, Holland).

\section{Experiment and measurements}

On 5 March 1998, we excavated all rooted rosettes from the artificial populations, removed their stolon branches, and pooled the rosettes. Randomly chosen individual rosettes were assigned to evenly spaced planting positions in each of thirty-two $31 \times 44-\mathrm{cm}$ trays filled with a soil mixture of the same composition as described above. The soil was covered with a thin layer of gravel to prevent the growth of algae and to reduce evaporation. Into 16 trays, we planted 40 rosettes (low-density treatment; 293 rosettes $\mathrm{m}^{-2}$ ) whereas into the other 16 trays, we planted 200 rosettes (high-density treatment; 1466 rosettes $\mathrm{m}^{-2}$ ). Both densities are within the range of rosette densities observed in the field (M. Fischer pers. obs.). Plants were watered at two-day intervals, and trays were randomly assigned to new positions in the plant room at two-week intervals.

We counted the number of rosettes, rooted rosettes and flowers (including flower buds and remnants of dead flowers) in a $12.5 \times 18.0-\mathrm{cm}$ area in the middle of each tray, to exclude border effects, 49,75 and $111 \mathrm{~d}$ after the start of the experiment (at the first census date, we counted only in 26 of the 32 trays). In each tray, we counted the number of rosettes and rooted rosettes of three randomly chosen clones (i.e., the product derived from a single individually planted rosette) $119-124 \mathrm{~d}$ after the start of the experiment. Both measures are positively correlated with clone biomass in $R$. reptans (number of rosettes: $r=0.753, P<0.001, N=32$; number of rooted rosettes: $r=0.559, P<0.001, N=32 ; M$. van Kleunen unpubl.). For ten randomly chosen rooted rosettes in each tray, we counted the number of leaves and measured the length of the longest leaf $75 \mathrm{~d}$ and $116 \mathrm{~d}$ after the start of the experiment. We estimated the size of rooted rosettes by multiplying the number of leaves by the length of the longest leaf. This measure of rosette size is positively correlated with rosette biomass in $R$. reptans $(r=0.836, P<0.0001, N=227$; M. van Kleunen unpubl.). We estimated the relative allocation to sexual and vegetative reproduction per tray by dividing the number of flowers and the number of rooted rosettes, respectively, by the total number of rosettes. To estimate which mode of reproduction was more pronounced, we calculated the ratio between the number of flowers and the number of rooted rosettes.

To study the effect of density on seed quality, we made hand-pollinations each second or third day during the experiment. With a pair of tweezers, we took several anthers from an open flower and moved them over the stigmata of several other open flowers within the same tray. This procedure was repeated for each open flower in the tray. Between the pollinations within different trays, we sterilized the pair of tweezers in a flame. About one month after the flowers had been pollinated, we harvested the seeds and stored them in closed plastic boxes in a refrigerator.

We partitioned all seeds per tray into portions of ten seeds. We randomly chose five portions of ten seeds per tray, weighed them, and calculated the mean mass of a seed. On 14 September 1998, we sowed all portions of ten seeds on a 1:3 mixture of sand and compost after the seeds had been incubated in a solution of $2 \mathrm{mg}$ $\mathrm{ml}^{-1}$ gibberellic acid for five days to break dormancy. We raised the air humidity above the seeds by covering the soil with perforated, transparent plastic foil. We sprayed the seeds and emerging seedlings with a fungicide (Previcur, Dr. R. Maag AG, Dielsdorf, Switzerland) twice during the experiment. Twenty-seven days after we had sown the seeds, we counted the number of seedlings. After this date, no further seeds germinated.

\section{Statistical analyses}

All variables were analysed with analyses of variance using the statistical package SPSS (SPSS Inc., Chicago, IL, USA). Variables that were measured repeatedly during the experiment were analysed with repeatedmeasures analyses of variance. In these analyses, the between-subject effects refer to trays, whereas the within-subject effects refer to census dates. Because Mauchly's tests revealed that there was no compound 


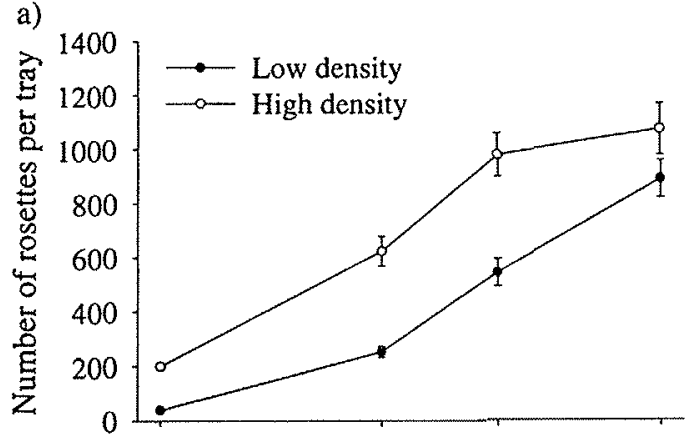

b)

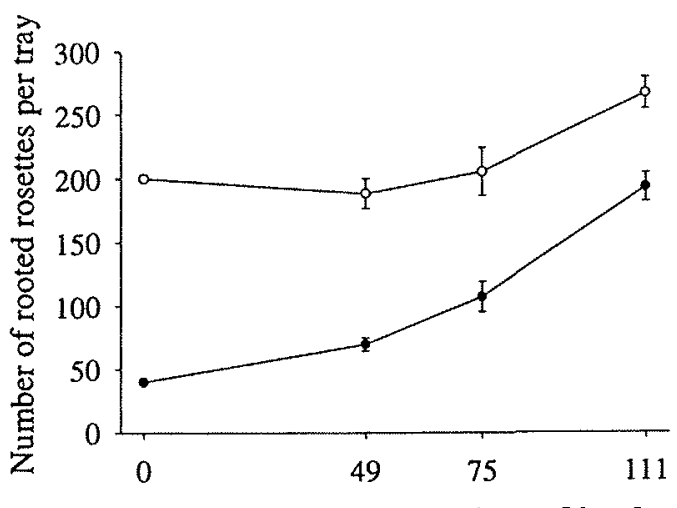

Time after start of experiment [days]

Fig. 1. The effect of density treatment on the mean number of (a) rosettes and of (b) rooted rosettes in the experiment with Ranunculus reptans. Measurements were made 49,75 , and 111 $\mathrm{d}$ after the start of the experiment. Parameter estimates are given $\pm 1 \mathrm{SE}$.

symmetry of the covariance matrices of the number of rosettes, of the number of rooted rosettes, and of the ratio between the number of flowering and rooted rosettes (Mauchly 1940), we corrected the degrees of freedom according to Greenhouse and Geisser (1959).

For the analyses of numbers of rosettes, and rooted rosettes, and of relative allocation to sexual and vegetative reproduction, we included data of 26 of the 32 trays (13 low density and 13 high density trays). In these 26 trays, we counted the number of rosettes, rooted rosettes and flowers also on day 49.

Variation in size among rosettes and among clones was quantified by calculating coefficients of variation (CV) in size traits for each tray. When we used Gini-coefficients (Weiner and Thomas 1986) to quantify the variation in size, we obtained qualitatively identical results (data not shown). Although coefficients of variation are generally not normally distributed, they did not deviate from normality in our study. Therefore, we analysed these data with analysis of variance. Moreover, we found that the significance of the effects of the density treatment on coefficients of variation did not change when we used non-parametric tests.

\section{Results \\ Density of rosettes and rooted rosettes}

During the experiment, densities of rosettes and rooted rosettes increased in both density treatments as a consequence of vegetative spread of the originally planted rosettes (i.e. clones) of $R$. reptans (Fig. 1; effect of census date in Table 1). The number of rooted rosettes decreased slightly in the high-density treatment between the start of the experiment and day 49. This indicates that some of the originally planted rosettes had died (Fig. 1b).

The number of rosettes and the number of rooted rosettes differed between the two density treatments throughout the experiment $(P<0.001$, Table 1 , also note the non-significant density treatment-by-census date interactions). On day 111 , the range of the number of rooted rosettes was $139-321$ and 182-381 for the low- and high-density treatments, respectively.

Table 1. Summary of analyses of variance of effects of density treatment and census date on actual densities of rosettes and rooted rosettes in the experiment with Ranunculus reptans. We used repeated-measures analyses of variance to study both $v a r i a t i o n$ between trays (between subject) and variation within trays (within subject). Significance levels of the within-subject effects are corrected by using the Greenhouse-Geisser $(\mathrm{G}-\mathrm{G})$ correction factor $\varepsilon$. $* * P<0.01, * * * P<0.001$.

\begin{tabular}{|c|c|c|c|c|c|c|c|c|c|}
\hline \multirow[t]{2}{*}{ Effect } & \multirow[t]{2}{*}{ df } & \multicolumn{4}{|c|}{ Number of rosettes } & \multicolumn{4}{|c|}{ Number of rooted rosettes } \\
\hline & & MS & $F$ & $P$ & G-G & MS & $F$ & $P$ & $\mathrm{G}-\mathrm{G}$ \\
\hline \multicolumn{10}{|l|}{ Between trays } \\
\hline Density treatment & 1 & 2200122 & 21.09 & $* * *$ & - & 212120 & 77.71 & $* * *$ & - \\
\hline Tray & 24 & 104327 & & & & 2730 & & & \\
\hline \multicolumn{10}{|l|}{ Within trays } \\
\hline Census date & 2 & 1553630 & 38.07 & $* * *$ & $* *$ & 68275 & 38.10 & $* * *$ & $* * *$ \\
\hline $\mathrm{D} \times \mathrm{C}$ & 2 & 61759 & 1.51 & & & 2378 & 1.33 & & \\
\hline Error & 48 & 40813 & & & & 1792 & & & \\
\hline
\end{tabular}


Table 2. The effect of density treatment on mean clone size (number of rosettes and number of rooted rosettes), and mean variation in clone size (coefficient of variation, CV) 119 after the start of the experiment with Ranunculus reptans. Parameter estimates are given together with $\pm 1 \mathrm{SE}$.

\begin{tabular}{lcc}
\hline Trait & Low density & High density \\
\hline $\begin{array}{l}\text { Number of rosettes per } \\
\text { clone }\end{array}$ & $44.1 \pm 4.9$ & $17.3 \pm 2.4$ \\
$\begin{array}{l}\text { Number of rooted } \\
\text { rosettes per clone }\end{array}$ & $6.8 \pm 0.9$ & $2.1 \pm 0.3$ \\
$\begin{array}{l}\mathrm{CV} \text { of number of } \\
\text { rosettes per clone }\end{array}$ & $0.61 \pm 0.08$ & $0.53 \pm 0.07$ \\
$\begin{array}{l}\mathrm{CV} \text { of number of rooted } \\
\text { rosettes per clone }\end{array}$ & $0.67 \pm 0.08$ & $0.37 \pm 0.06$ \\
\hline
\end{tabular}

a)

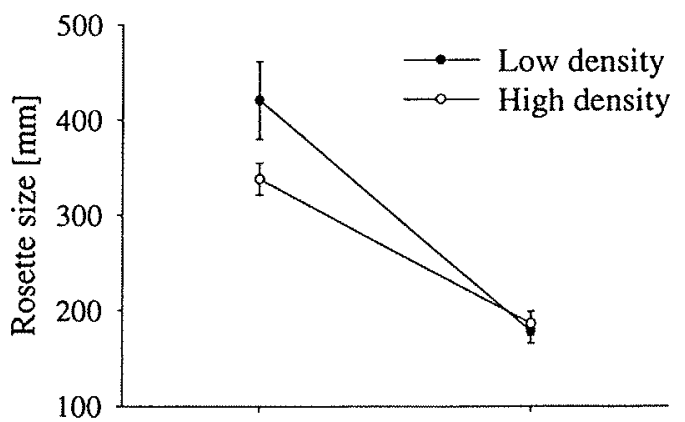

b)

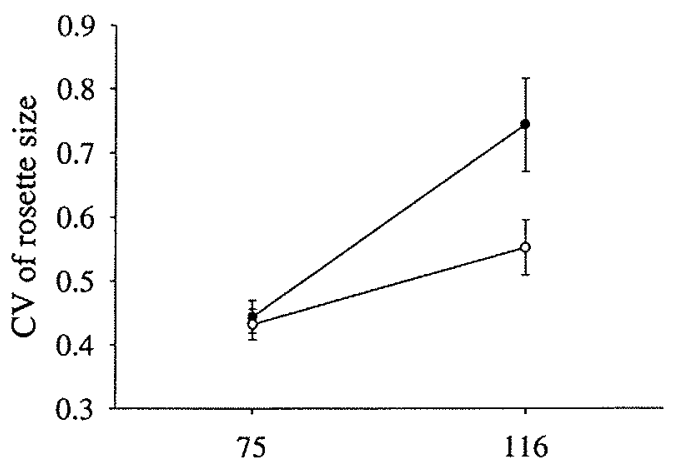

Time after start of experiment [days]

Fig. 2. The effect of density treatment on (a) the mean size of rooted rosettes, and on (b) the mean coefficient of variation (CV) of rosette size in the experiment with Ranumculus reptans. Measurements were made 75 and $116 \mathrm{~d}$ after the start of the experiment. Rosette size denotes the product of the number of leaves and the length of the longest leaf. Parameter estimates are given $+1 \mathrm{SE}$

\section{Mean and variation in clone size}

On day 119 , clones in the low-density treatment had $155 \%$ and $227 \%$ more rosettes and rooted rosettes, respectively, than clones in the high-density treatment
(Table 2; rosettes: $F_{1.30}=24.0, \quad P<0.001$; rooted rosettes: $F_{1,30}=23.0, P<0.001$ ).

In the low-density treatment, variation in the number of rosettes per clone, and variation in the number of rooted rosettes per clone, expressed as coefficients of variation, was $15 \%$ and $83 \%$ higher, respectively, than in the high-density treatment (Table 2; coefficient of variation in number of rosettes: $F_{130}=0.52, P>0.05$; coefficient of variation in number of rooted rosettes $F_{1,30}=9.38, P<0.01$ ). This indicates that intraspecific competition reduced size variation among clones.

\section{Mean and variation in rosette size}

On day 75 , rooted rosettes had, averaged over both density treatments, 10.6 leaves of which the longest leaf was $35.7 \mathrm{~mm}$. Thereafter, these values decreased. On day 115 , rooted rosettes had on average 5.9 leaves of which the longest leaf was $29.1 \mathrm{~mm}$. The size of rooted rosettes, estimated as the product of the number of leaves and the length of the longest leaf, was larger in the low-density treatment than in the high-density treatment on day 75 (Fig. 2a). This effect had disappeared by day 115 , which is reflected in a marginally significant density treatment-by-date interaction (Fig. 2a, Table 3).

Size variation among rooted rosettes, expressed as coefficient of variation, increased significantly between day 75 and day 115 (Fig. 2b; effect of census date in Table 3). On day 75, no effect of the density treatment on size variation among rooted rosettes was evident, whereas on day 115 size variation among rooted rosettes was significantly larger in the low-density treatment than in the high-density treatment (Fig. 2b; effect of density treatment in Table 3 ).

\section{Relative allocation to sexual and vegetative reproduction}

The proportion of flowering rosettes (i.e. relative allocation to sexual reproduction) increased from 0.29 to 0.37 in the low-density treatment between day 49 and day 111 (Fig. 3a). In the high-density treatment, the proportion of flowering rosettes first increased from 0.38 to 0.49 between day 49 and day 75 , and thereafter it decreased to 0.37 by day 111 (Fig. 3a; marginally significant density treatment-by-census date interaction in Table 4). Averaged over time, the proportion of flowering rosettes was $19 \%$ higher in the high-density treatment than in the low-density treatment (significant density treatment effect in Table 4).

The proportion of rooted rosettes (i.e. relative allocation to vegetative reproduction) first decreased from 0.29 to 0.21 and from 0.32 to 0.21 in the low and high-density treatments, respectively, between day 49 and day 75 , and thereafter it increased to 0.23 and 0.28 , respectively, by day 111 (Fig. 3b; significant census date 
effect in Table 4). Averaged over time, the proportion of rooted rosettes was $13 \%$ higher in the high-density treatment than in the low-density treatment (Fig. 3b; marginally significant density treatment effect in Table 4).

The ratio between the number of flowers and the number of rooted rosettes (i.e. the ratio between sexual and vegetative reproduction) in the high-density treatment was higher than in the low-density treatment during the largest part of the experiment (day 49-75; Fig. 3c). This suggests that reproduction is shifted towards the sexual mode at higher densities. At the end of the experiment (day 111), when the relative difference in density of rosettes between both density treatment had diminished, the ratio between the number of flowers and the number of rooted rosettes was higher in the low-density treatment than in the high-density treatment (Fig. 3c). As a consequence, averaged over time, the effect of density on this ratio was not significant (Table 4).

\section{Seed mass and germination percentage}

The average mass of a seed produced in the high-density treatment $(0.55 \pm 0.01 \mathrm{mg})$ tended to be higher than the average mass of a seed produced in the low-density treatment $\left(0.51 \pm 0.01 \mathrm{mg}, F_{1,30}=3.08, P<0.1\right)$.

At the end of the germination experiment, i.e. after $27 \mathrm{~d}, 31 \%$ of the seeds had germinated. The germination percentage was significantly higher for seeds from the high-density treatment $(31.2 \pm 1.0)$ than for seeds from the low-density treatment $\left(25.2 \pm 2.2, F_{1.30}=7.25\right.$, $P<0.05)$. This indicates that in the high-density treatment, plants of $R$. reptans produced seeds of higher quality than in the low-density treatment.

\section{Discussion}

\section{Mean size and size variation of clones}

Clones in the low-density treatment of our experiment had produced more rosettes and rooted rosettes than clones in the high-density treatment. This indicates that density through an increase in intraspecific competition has negative effects on the fitness of genets of $R$. reptans. As a consequence of the higher growth rate of clones in the low-density treatment, the relative difference in rosette density decreased between both density treatments. As anticipated, however, the absolute difference in rosette density did not disappear during the experiment (Fig. 1).

The variation in the size of clones in the high-density treatment of our experiment was lower than in the low-density treatment (Table 2). This suggests that, although intraspecific competition decreases absolute fitness of genets of $R$. reptans, it does not increase differences in relative fitness among genets. This indicates that competition between clones of $R$. reptans is symmetric rather than asymmetric (Weiner and Thomas 1986, Weiner 1988). Probably, as has been suggested for other clonal plants (de Kroon et al. 1992; but see Schwinning and Weiner 1998), competition for light is relatively low in $R$. reptans because clones do not overtop each other as a consequence of limited height growth. In 14 of the 15 reported species in a review of Weiner and Thomas (1986), size variation increased with density. However, they do not give information on the degree of clonality of these species. The absence of an increase in size variation with density has been reported for the clonal plants Brachypodium pinnatum, Carex flacca, and Solidago altissima (de Kroon et al. 1992, Meyer and Schmid 1999).

A reduction in size variation of clones with increasing density concomitantly reduced variation in the number of rooted rosettes (i.e. vegetative fecundity), and because the number of flowering rosettes is strongly positively correlated with the number of rooted rosettes, most likely also variation in the number of flowering rosettes (i.e. sexual fecundity) of $R$. reptans. Because effective population size decreases with increasing variation in fecundity (Heywood 1986, Thomas and Bazzaz 1993, Hartl and Clark 1994), genetic drift is likely to be less pronounced at higher densities in $R$. reptans. Moreover, the response to selec-

Table 3. Summary of analyses of variance of effects of density treatment and census date on rosette size (number of leaves $\times$ length of the longest leaf) and the variation in rosette size (expressed as coefficient of variation, $C V$ ) in the experiment with Ranunculus reptans. We used repeated-measures analyses of variance to study both variation between trays (between subject) and variation within trays (within subject). $+P<0.1, * P<0.05, * * * P<0.00 \mathrm{I}$.

\begin{tabular}{|c|c|c|c|c|c|c|c|}
\hline \multirow[t]{2}{*}{ Effect } & \multirow[t]{2}{*}{ df } & \multicolumn{3}{|c|}{ Rosette size } & \multicolumn{3}{|c|}{$\mathrm{CV}$ of rosette size } \\
\hline & & MS & $F$ & $P$ & MS & $F$ & $P$ \\
\hline \multicolumn{8}{|l|}{ Between trays } \\
\hline Density treatment & 1 & 22374.3 & 2.76 & & 0.150 & 5.02 & * \\
\hline Tray & 30 & 8113.2 & & & 0.030 & & \\
\hline \multicolumn{8}{|l|}{ Within trays } \\
\hline Census date & 1 & 621329.3 & 61.89 & $* * *$ & 0.494 & 16.01 & $* * *$ \\
\hline $\mathrm{D} \times \mathrm{C}$ & 1 & 33058.3 & 3.29 & + & 0.115 & 3.73 & + \\
\hline Error & 30 & 10039.3 & & & 0.031 & & \\
\hline
\end{tabular}


a)

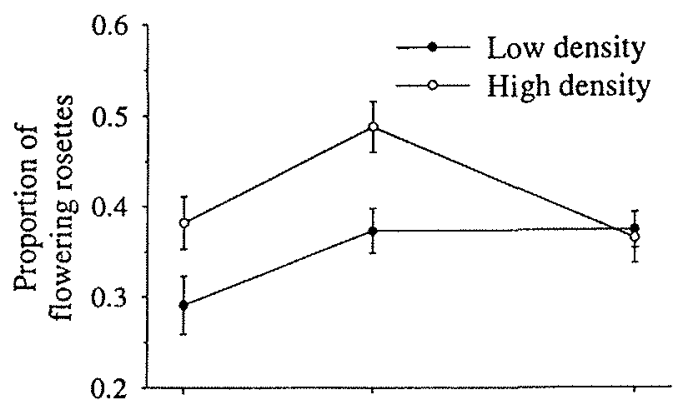

b)
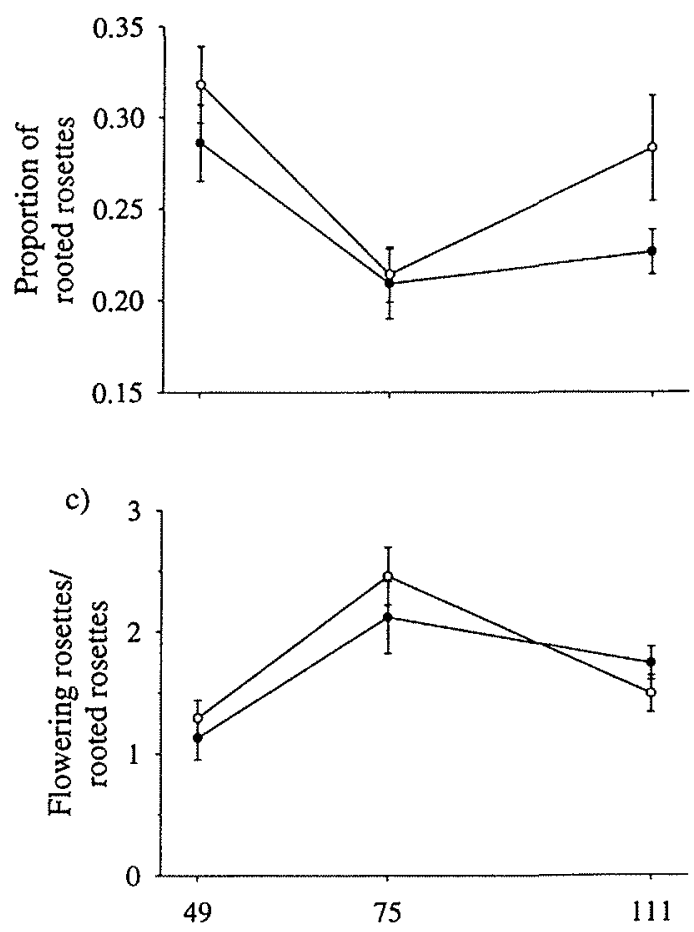

Time after start of the experiment [days]

Fig. 3. The effect of density treatment on the mean proportion of (a) flowering rosettes, (b) rooted rosettes and (c) the ratio between the number of flowering and rooted rosettes in the experiment with Ranunculus reptans. Measurements were made 49,75 , and $111 \mathrm{~d}$ after the start of the experiment. Parameter estimates are given $\pm 1 \mathrm{SE}$

tion is likely to decrease with increasing density in $R$. reptans because it increases with increasing variation in fecundity (Thomas and Bazzaz 1993, Falconer and Mackay 1996). These effects of density on genetic drift and on the response to selection suggest that genetic differentiation between high-density populations will be lower than between low-density populations of $R$. reptans.

\section{Mean size and size variation of rosettes}

Rosettes of $R$. reptans were larger in the low-density treatment than in the high-density treatment $75 \mathrm{~d}$ after the start of the experiment. This indicates that intraspecific competition reduces not only the number of vegetative offspring but also the size of ramets. However, $115 \mathrm{~d}$ after the start of the experiment, the difference in rosette size between the two density treatments had disappeared (Fig. 2a).

The larger variation in rosette size in the low-density treatment than in the high-density treatment (Fig. 2b) may suggest that competition among ramets of $R$. reptans is also symmetric, as has also been reported for Phragmites australis, Polygonum weyrichii, and $P$. cuspidatum (Hara et al. 1993, Suzuki 1994), but not for Carex flacca and Brachypodium pinnatum (de Kroon et al. 1992). The overall increase in variation in rosette size during our experiment is probably caused by the production of new daughter ramets, which are initially smaller than the mother ramets. Therefore, the larger variation in rosette size in the low-density treatment than in the high-density treatment can most likely be attributed to a higher production rate of daughter rosettes in the low-density treatment than in the highdensity treatment (de Kroon 1993).

\section{Relative allocation to sexual and vegetative reproduction}

The relative allocation to sexual reproduction was higher when the population of $R$. reptans grew in the high-density treatment than when it grew in the lowdensity treatment. Many plants have a minimal size requirement for flowering, and as a consequence, when plants grow and move along their allometric trajectory, they generally increase the relative allocation to sexual reproduction (Weiner 1988, Schmid and Weiner 1993). This has also been found in $R$. reptans (M. van Kleunen unpubl.). Clones of $R$. reptans were smaller in the high-density treatment than in the low-density treatment, and could therefore be expected to have a lower rather than higher relative allocation to sexual reproduction under high density. From the opposite pattern found in our experiment, we conclude that the change in relative allocation to sexual reproduction is a direct response to density rather than an indirect consequence of growth.

Seed mass and germination percentages were also higher for seeds of $R$. reptans produced in the high-density treatment than for seeds produced in the low-density treatment. Although seed mass may trade-off with 
seed number in $R$. reptans (Prati 1998), this further indicates that the allocation to sexual reproduction was stimulated under high density through both an increased proportion of flowering rosettes and a higher seed quality.

Increased investment to sexual reproduction under high density may be beneficial, as seeds enable the dispersion to more favourable sites (Abrahamson 1975, 1980, Loehle 1987, Gardner and Mangel 1999). Moreover, sexual reproduction results in a high genetic diversity and thus enhances the chance that some of the offspring will have a higher performance in the high-density environment than their parents. Furthermore, the increased quality of seeds produced under high density may enhance the probability of local establishment of sexually produced offspring (Haig and Westoby 1988).

In clonal plants, there seems to be no general adaptive response of reproductive allocation to density as both an increase in relative allocation to sexual reproduction and an increase in relative allocation to vegetative reproduction may be beneficial (Ogden 1974, Abrahamson 1975, 1980, Williams 1975, Loehle 1987, Gardner and Mangel 1999). Outcomes of selection under low and high density (i.c. $r$ - and $K$-selection) may depend on whether plants have a spreading (guerrilla sensu Lovett Doust 1981) or a compact (phalanx sensu Lovett Doust 1981) growth form (Sackville Hamilton et al. 1987). Similarly, the direct effect of density on reproductive allocation may also depend on the clonal growth form. In clonal plants with a guerrilla growth form, such as $R$. reptans, vegetative reproduction may be as effective as or even more effective than sexual reproduction in colonizing the available space under low density (Sackville Hamilton et al. 1987). In clonal plants with a phalanx growth form, vegetative reproduction is not an effective means to colonize the available space under low density (Sackville Hamilton et al. 1987), whereas it may be an effective means to increase the competitive strength under high density (Schmid and Harper 1985).

In guerrilla species, it may be advantageous to shift reproductive allocation from vegetative reproduction to sexual reproduction with increasing density, whereas the opposite response may be advantageous in phalanx species. Indeed, studies reported in the literature show that phalanx species generally decrease the allocation to sexual reproduction with increasing density (Table 5), which, however, might also be a consequence of allometric growth (Weiner 1988). Although these studies do not report data on vegetative reproductive allocation, the results suggest that phalanx species generally decrease the ratio between sexual and vegetative reproduction with increasing density. For guerrilla species, such as $R$. reptans, the studies reported in the literature are less equivocal (Table 5). Nevertheless, they suggest that, in contrast to phalanx species, most guerrilla species increase the ratio between sexual and vegetative reproduction in response to density.

\section{Conclusions}

We conclude that intraspecific competition in $R$. reptans may affect evolutionary processes, such as genetic drift and the response to selection, as a consequence of a reduced variation in clone size. Moreover, we conclude that intraspecific competition affects the clonal life history of $R$. reptans, and that reproduction is shifted towards the sexual mode at higher densities. Given the fact that rosette densities of $R$. reptans can be high in its natural habitat, our study suggests that intraspecific competition is an important factor in the evolution of the clonal life history, at least of $R$. reptans.

Table 4. Summary of analyses of variance of effects of density treatment and census date on the relative allocation to sexual reproduction, the relative allocation to vegetative reproduction, and the ratio between the number of flowering and rooted rosettes in the experiment with Ranunculus reptans. We used repeated-measures analyses of variance to study both variation between trays (between subject) and variation within trays (within subject). For the ratio between the number of flowering and rooted rosettes, significance levels of the within-subject effects are corrected by using the Greenhouse-Geisser (G-G) correction factor $\varepsilon .+P<0.1, * * P<0.01,{ }^{* * *} P<0.001$.

\begin{tabular}{|c|c|c|c|c|c|c|c|c|c|c|c|}
\hline \multirow[t]{2}{*}{ Effect } & \multirow[t]{2}{*}{ df } & \multicolumn{3}{|c|}{$\begin{array}{l}\text { Proportion of flowering } \\
\text { rosettes }\end{array}$} & \multicolumn{3}{|c|}{$\begin{array}{l}\text { Proportion of rooted } \\
\text { rosettes }\end{array}$} & \multicolumn{4}{|c|}{ Flowering rosettes/rooted rosettes } \\
\hline & & MS & $F$ & $P$ & MS & $F$ & $P$ & MS & $F$ & $P$ & $\mathrm{G}-\mathrm{G}$ \\
\hline \multicolumn{12}{|l|}{ Between trays } \\
\hline Density treatment & 1 & 0.06691 & 4.18 & $* * *$ & 0.03187 & 3.14 & + & 0.052 & 0.05 & & - \\
\hline Tray & 24 & 0.01603 & & & 0.01014 & & & 1.013 & & & \\
\hline \multicolumn{12}{|l|}{ Within trays } \\
\hline Census date & 2 & 0.05937 & 5.83 & $* *$ & 0.05698 & 12.93 & $* * *$ & 7.893 & 20.94 & $* * *$ & $* * *$ \\
\hline $\mathrm{D} \times \mathrm{C}$ & 2 & 0.03214 & 3.16 & + & 0.00211 & 0.48 & & 0.328 & 0.87 & & \\
\hline Error & 48 & 0.01018 & & & 0.00441 & & & 0.377 & & & \\
\hline
\end{tabular}


Table 5. Summary of studies on the effect of density on the allocation to sexual and to vegetative reproduction, and on the ratio between sexual and vegetative reproduction in clonal plants with different growth forms (phalanx vs guerrilla). $+:$ positive effect of density, - : negative effect of density, 0 : no significant effect of density, and?: effect not given.

\begin{tabular}{|c|c|c|c|c|}
\hline \multirow[t]{2}{*}{ Species and growth form } & \multicolumn{3}{|c|}{ Reproductive allocation } & \multirow[t]{2}{*}{ Reference } \\
\hline & Sexual & Vegetative & Sexual/vegetative & \\
\hline \multicolumn{5}{|l|}{ Phalanx growth form: } \\
\hline Plantago major & - & $?$ & ? & Hawthom and Cavers 1982 \\
\hline Bromus erectus & - & $?$ & $?$ & Stephan 2000 \\
\hline Bellis perennis & - & $?$ & $?$ & Schmid and Harper 1985 \\
\hline Elymus lanceolatus ssp. wawawaiensis & - & $?$ & $?$ & Humphrey and Pyke 1998 \\
\hline \multicolumn{5}{|l|}{ Guerrilla growth form: } \\
\hline Ranunculus reptans & + & + & + & this study \\
\hline Cyperus rotundus & - & + & - & Williams et al, 1977 \\
\hline Prunella vulgaris & + & $?$ & $?$ & Schmid and Harper 1985 \\
\hline Elymus lanceolatus ssp. lanceolatus & - & $?$ & $?$ & Humphrey and Pyke 1998 \\
\hline Hieracium pilosella & $+\dagger$ & $?$ & $?$ & Bishop and Davy 1985 \\
\hline Tussilago farfara & 0 & - & + & Ogden 1974 \\
\hline Fragaria virginiana & 0 & - & + & Holler and Abrahamson 1977 \\
\hline Hieracium floribundum & 0 & - & + & $\begin{array}{l}\text { Thomas } 1974 \text {, cited in Abra- } \\
\text { hamson } 1975\end{array}$ \\
\hline Carex flacca & + & $?$ & $?$ & Stephan 2000 \\
\hline
\end{tabular}

$f:$ in this study the allocation to sexual reproduction decreased when density was higher than the density observed in nature.

Acknowledgements - We thank Rahel Schmid, Philipp Kocyan and Thomas Pfluger for practical assistance, and Hans de Kroon for comments on the manuscript. Penelope Oertli-Barnett helped to improve the English and structure of the ms. Wo acknowledge financial support by the Swiss National Science Foundation (Grant 31-49728.96).

\section{References}

Abrahamson, W. G. 1975. Reproductive strategies in dewberries. - Ecology 56: $721-726$.

Abrahamson, W. G. 1980. Demography and vegetative reproduction. - In: Solbrig, O. T. (ed.), Demography and evolution in plant populations. Blackwell, pp. 89-106.

Begon, M. 1982. Density and individual fitness: asymmetric competition. - In: Shorrocks, B. (ed.), Evolutionary ecology. Blackwell, pp. 175-194.

Bishop, G. F, and Davy, A, J, 1985. Density and the commitment of apical meristems to clonal growth and reproduction in Hieracium pilosella. - Oecologia 66: 417-422.

de Kroon, H. 1993. Competition between shoots in stands of clonal plants. - Plant Spec. Biol. 8: 85-94.

de Kroon, H., Hara, T. and Kwant, R. 1992. Size hierarchies of shoots and clones in clonal herb monocultures: do clonal and non-clonal plants compete differently? - Oikos 63: $410-419$

Dong, M. and de Kroon, H. 1994. Plasticity in morphology and biomass allocation in Cynodon dactylon, a grass forming stolons and rhizomes. - Oikos 70: 99-106.

Falconer, D. S. and Mackay, T. F. C. 1996. Introduction to quantitative genetics. - Longman.

Fischer, M., Husi, R., Prati, D., Peintinger, M. et al. 2000 RAPD variation among and within small and large populations of the rare clonal plant Ranumculus reptans (Ranunculaceae) - Am. J. Bot 87: 1128-1137.

Gardner, S. N. and Mangel, M. 1999. Modeling investments in seeds, clonal offspring, and translocation in a clonal plant. - Ecology 80: 1202-1220.

Gottlieb, L. D. 1977. Genotypic similarity of large and small individuals in a natural population of the annual plant Stephanomeria exigua ssp. coronaria (Compositae). - J. Ecol. 65: 127-134

Greenhouse, S. W. and Geisser, S. 1959. On methods in the analysis of profile data. - Psychometri 24: 95-112.
Haig, D. and Westoby, M. 1988. Inclusive fitness, seed resources, and maternal care. - In: Lovett Doust, J. and Lovett Doust, L, (eds), Plant reproductive ecology, Oxford Univ. Press, pp. 60-79.

Hara, T. 1994. Growth and competition in clonal plants persistence of shoot populations and species diversity. Folia Geobot. Phytotax. 29: 181-201.

Hara, T, van der Toorn, J. and Mook, J. H. 1993. Growth dynamics and size structure of shoots of Phragmites aus tralis, a clonal plant. - J. Ecol. 81: 47-60.

Harper, J. L. 1977. Population biology of plants. - Academic Press.

Hartl, D. L. and Clark, A. G. 1994. Principles of population genetics. - Sinauer.

Hartnett, D. C. 1990. Size-dependent allocation to sexual and vegetative reproduction in four clonal composites. - Oecologia 84: $254-258$.

Hawthorn, W. R. and Cavers, P. B. 1982. Dry weight and resource allocation patterns among individuals in populations of Plantago major and P. rugelii. - Can. J. Bot. 60; $2424-2439$.

Hess, H. E., Landolt, E. and Hirzel, R, 1980. Flora der Schweiz. Vol. 2. - Birkhäuser.

Heywood, J. S. 1986. The effect of plant size variation on genetic drift in populations of annuals, - Am. Nat. 127; $851-861$.

Holler, L. C. and Abrahamson, W. G. 1977. Seed and vegetative reproduction in relation to density in Fragaria virginiana (Rosaceae). - Am. J. Bot. 64: 1003-1007.

Humphrey, L. D. and Pyke, D. A. 1998. Demographic and growth responses of a guerrilla and a phalanx perennial grass in competitive mixtures. - J. Ecol. 86: 854-865.

Loehle, C. 1987. Partitioning of reproductive effort in clonal plants: a benefit-cost model. - Oikos 49: 199-208.

Lovett Doust, L. 1981. Population dynamics and local specialization in a clonal perennial (Ranunculus reptans). I. The dynamics of ramets in contrasting habitats. - J. Ecol. 69: $743-755$.

MacArthur, R. H. and Wilson, E. O. 1967. The theory of island biogeography. - Princeton Univ. Press.

Mauchly, J. W. 1940. Significance test for sphericity of a normal n-variate distribution. - Ann. Math. Stat. 29: 204-209.

Meyer, A. H. and Schmid, B. 1999. Experimental demography of rhizome populations of establishing clones of Solidago altissima. -- J. Ecol. 87: 42-54. 
Ogden, J. 1974. The reproductive strategy of higher plants: II The reproductive strategy of Tussilago farfara L. - J. Ecol 62: $291-324$

Prati, D. 1998. The genetics and life-history evolution of the clonal plant Ranunculus reptans. - PhD thesis. - Univ. of Zürich.

Prati, D. and Peintinger, M. 2000. Biological flora of central Europe: Ranunculus reptans L. - Flora 195: 135-145

Sackville Hamilton, N. R., Schmid, B. and Harper, J. L. 1987. Life-history concepts and the population biology of clonal organisms. - Proc. R. Soc. Lon. 232: 35-57.

Schmid, B. 1990. Some ecological and evolutionary consequences of modular organization and clonal growth in plants. - Evol. Trends Plants 4: 25-34.

Schmid, B. and Harper, J. L. 1985. Clonal growth in grassland perennials. 11. Growth form and fine-scale colonization ability. - J. Ecol. 73: 809-818.

Schmid, B. and Weiner, J. 1993. Plastic relationships between reproductive and vegetative mass in Solidago altissima. Evolution 47: 61-74.

Schmid, B., Bazzaz, F. A. and Weiner, J, 1995. Size dependency of sexual reproduction and of clonal growth in two perennial plants. - Can. J. Bot. 73: 1831-1837.

Schwinning, S. and Weiner, J. 1998. Mechanisms determining the degree of size-asymmetry in plant competition. - Oecologia 113: $447-455$

Stephan, M. A. 2000. Population dynamics and interactions under atmospheric CO2-increase and biodiversity loss. PhD thesis. - Univ. of Zürich.
Suzuki, J. 1994. Shoot growth dynamics and the mode of competition of two rhizomatous Polygonum species in the alpine meadow of Mt. Fuji. - Folia Geobot. Phytotax. 29 $203-216$

Suzuki, J. and Hutchings, M. J. 1997. Interactions between shoots in clonal plants and the effect of stored resources on the structure of shoot populations. - In: de Kroon, $\mathrm{H}$, and van Groenendael, J. (eds), The ecology and evolution of clonal plants. Backhuys Publ, pp. 311-329.

Thomas, A. G. 1974. Reproductive strategies of Hieracium. Plant Population Dynamics Symposium, AlBS Meetings, Tempe, AZ.

Thomas, S. C. and Bazzaz, F. A. 1993. Some ecological and evolutionary consequences of modular organization and clonal growth in plants. - Ecol. Monogr. 63: 231-249.

Watson, M. A. 1984, Developmental constraints: effect on population growth and patterns of resource allocation in a clonal plant. - Am. Nat. 123: 411-426.

Weiner, J. 1988. The influence of competition on plant reproduction. - In: Lovett Doust, J. and Lovett Doust, L. (eds), Plant reproductive ecology. Oxford Univ. Press, pp. 228 245.

Weiner, J. and Thomas, S. C. 1986. Size variability and competition in plant monocultures. - Oikos 47: $211-222$. Williams, G. C. 1975. Sex and evolution. - Princeton Univ. Press.

Williams, R, D. Quimby, P. C. and Frick, K. F. 1977. Intraspecific competition of purple nutsedge (Cyperus rotundus) under greenhouse conditions. - Weed Sci. 25: 477-481. 